Article

\title{
Effect of Axial In-Situ Stress in Deep Tunnel Analysis Considering Strain Softening and Dilatancy
}

\author{
Kang Yi ${ }^{1,2,3}$, Zhenghe Liu ${ }^{4, *}$, Zhiguo Lu ${ }^{2,3,5}$, Junwen Zhang ${ }^{1, *}$ and Shuangyong Dong ${ }^{2,3}$ \\ 1 School of Energy \& Mining Engineering, China University of Mining and Technology (Beijing), \\ Beijing 100083, China; bqt1800101029@student.cumtb.edu.cn \\ 2 Mining and Designing Branch, China Coal Research Institute, Beijing 100013, China; \\ cumtblzg@163.com (Z.L.); shuangyong_dong@163.com (S.D.) \\ 3 Coal Mining and Designing Department, Tiandi Science and Technology Co., Ltd., Beijing 100013, China \\ 4 Key Laboratory of In-situ Property-improving Mining of Ministry of Education, Taiyuan University of \\ Technology, Taiyuan 030024, China \\ 5 State Key Laboratory of Coal Mining and Clean Utilization, China Coal Research Institute, \\ Beijing 100013, China \\ * Correspondence: liuzhenghe@tyut.edu.cn (Z.L.); zhangjw@cumtb.edu.cn (J.Z.)
}

Received: 17 February 2020; Accepted: 20 March 2020; Published: 22 March 2020

\begin{abstract}
In many previous tunnel analyses, the axial in-situ stress was ignored. In this work, its effect on the deformation and failure of the surrounding rock of a deep tunnel was revealed, considering the objective strain softening and dilatancy behavior of the surrounding rock. Analysis based on the incremental plastic flow theory was conducted, and C++ was used to write a constitutive model for numerical simulation to verify and further analyze this effect. Then, the results were validated by the field monitoring data of a coal mine gateway. Results show that the effect of the axial in-situ stress $\sigma_{\mathrm{a} 0}$ is more significant when strain softening is considered, compared with the results of a perfectly elastoplastic model. When the axial stress $\sigma_{\mathrm{a}}$ is $\sigma_{1}$ or $\sigma_{3}$ at the initial yield, an increase or decrease in $\sigma_{\mathrm{a} 0}$ intensifies the deformation and failure of the surrounding rock. When $\sigma_{\mathrm{a}}$ is $\sigma_{2}$ at the initial yield, 3D plastic flow partly controlled by $\sigma_{\mathrm{a}}$ may occur, and an increase in $\sigma_{\mathrm{a} 0}$ intensifies the deformation and failure of the surrounding rock. The effect of $\sigma_{\mathrm{a} 0}$ will be amplified by considering dilatancy. Considering both strain softening and dilatancy, when $\sigma_{\mathrm{a} 0}$ is close to the tangential in-situ stress $\sigma_{\mathrm{t} 0}$ or significantly greater than $\sigma_{\mathrm{t} 0}$ (1.5 times), $\sigma_{\mathrm{a}}$ will be $\sigma_{2}$ or $\sigma_{1}$ at the initial yield, and then 3D plastic flow will occur. In the deformation prediction and support design of a deep tunnel, $\sigma_{\mathrm{a} 0}$ should not be ignored, and the strain softening and dilatancy behavior of the surrounding rock should be accurately considered.
\end{abstract}

Keywords: deep tunnel; axial in-situ stress; strain softening; dilatancy; constitutive model

\section{Introduction}

Mineral resources are an important source of energy, and their development is shifting to deeper areas [1-3], increasing the depths of the tunnels excavated for the exploitation of mineral resources. Statistically, deep tunnels account for approximately $30 \%$ of the tunnels constructed each year, and $70 \%$ of these tunnels will need to be repaired owing to large deformations of the surrounding rock masses under high in-situ stress conditions, which greatly increases costs [4]. It is therefore important to correctly evaluate the effect of in-situ stress on a deep tunnel to more accurately predict tunnel deformation and better support design.

A deep tunnel problem is often simplified to a plane strain problem, and the tangential stress $\sigma_{\mathrm{t}}$ and radial stress $\sigma_{\mathrm{r}}$ are considered to be the maximum principal stress $\sigma_{1}$ and minimum principal 
stress $\sigma_{3}$, respectively, while the axial stress $\sigma_{\mathrm{a}}$ is assumed to be the intermediate principal stress $\sigma_{2}$. In many previous analyses [5-7], the effect of $\sigma_{\mathrm{a}}$ was not considered, and the axial in-situ stress $\sigma_{\mathrm{a} 0}$, the initial value of $\sigma_{\mathrm{a}}$, was ignored. However, Lu, A.-Z. et al. [8] pointed out that when $\sigma_{\mathrm{a} 0}$ exceeds a certain critical value, it has an effect on the calculation results, and they then defined the problem as a quasi-plane strain problem. Wang, S. et al. [9] considered that the greater the strength drop of the surrounding rock or the greater the difference between $\sigma_{\mathrm{a} 0}$ and the uniform in-plane in-situ stress, the more significant the effect of $\sigma_{\mathrm{a} 0}$ will be. Guan, K. et al. [10] pointed out that $\sigma_{\mathrm{a} 0}$ will cause axial plastic flow, leading to an increase in the deformation of the surrounding rock. However, the abovementioned studies focused on only circular tunnels and either ignored or incompletely considered the post-peak mechanical behavior of the rock masses.

Extensive laboratory tests and field observations [11-15] show that a strain softening model can better describe the post-peak mechanical behavior of most rock masses than perfectly elastoplastic and elasto-brittle-plastic models can. Dilatancy is closely associated with the deformation and failure of a rock mass [16-18]. Many rock mechanical tests [19-21] show that a rock mass exhibits significant dilatancy in the post-peak stage and that the dilation angle strongly depends on the confining stress and plastic shear strain, decreasing nonlinearly with an increase in the confining stress or plastic shear strain. The surrounding rock of a deep tunnel has a large post-peak zone under high in-situ stress conditions [22,23], and strain softening and dilatancy, as the two main characteristics of the post-peak mechanical behavior of a rock mass, show a significant synergistic effect [24]; thus, they should both be accurately considered in a deep tunnel analysis [25].

To reveal the effect of the axial in-situ stress on the deformation and failure of the surrounding rock of a deep tunnel, this paper considers the strain softening and dilatancy of the surrounding rock and analyzes a more common rectangular tunnel [17] based on the incremental plastic flow theory under perfectly elastoplastic, considering only dilatancy, considering only strain softening and considering both strain softening and dilatancy, for a total of four conditions. Then, a numerical simulation is conducted to verify and further analyze the effect: a constitutive model considering nonlinear strain softening and two-parameter dilation angle is written in $\mathrm{C}++$, and this constitutive model is combined with the dynamic relaxation method in FLAC ${ }^{3 \mathrm{D}}$ to analyze the effect of the axial in-situ stress on the surface displacement and the plastic zone depth of a deep rectangular tunnel under the abovementioned four conditions. Finally, the results of the theoretical analysis and numerical simulation are verified by the field monitoring data.

Mineral resources, such as coal and petroleum, occur in the earth's crust, so the in-situ stress has an important impact on their exploitation [26,27]. In this work, the effect of the axial in-situ stress on a deep tunnel excavated for the exploitation of mineral resources is evaluated, and a novel constitutive model is developed to accurately predict the deformation and failure of the tunnel surrounding rock, which can improve the rationality of the preliminary design of a deep tunnel, reduce the repair rate, thus reduce cost and improve production efficiency.

\section{Theoretical Analysis}

\subsection{Description of the Problem}

To exclude other influencing factors, this paper studies a rectangular tunnel excavated in a homogeneous mudstone, and the axial in-situ stress $\sigma_{\mathrm{a} 0}$, vertical in-situ stress $\sigma_{\mathrm{v} 0}$ and lateral in-situ stress $\sigma_{\mathrm{h} 0}$ are the principal stresses before excavation, as shown in Figure 1. For a rectangular tunnel, the displacement and the plastic zone depth at the middle of the roof are generally larger, and because of symmetry, the axial stress $\sigma_{\mathrm{a}}$, vertical stress $\sigma_{\mathrm{v}}$ and lateral stress $\sigma_{\mathrm{h}}$ at these positions are always the principal stresses during the equilibrium process after the excavation. Therefore, in this section, a microunit at the middle of the roof is taken as an example for analysis. Then, $\sigma_{\mathrm{h}}$ is the tangential stress $\sigma_{\mathrm{t}}$, which is loading during the equilibrium process, and $\sigma_{\mathrm{v}}$ is the radial stress $\sigma_{\mathrm{r}}$, which is unloading during the equilibrium process. 

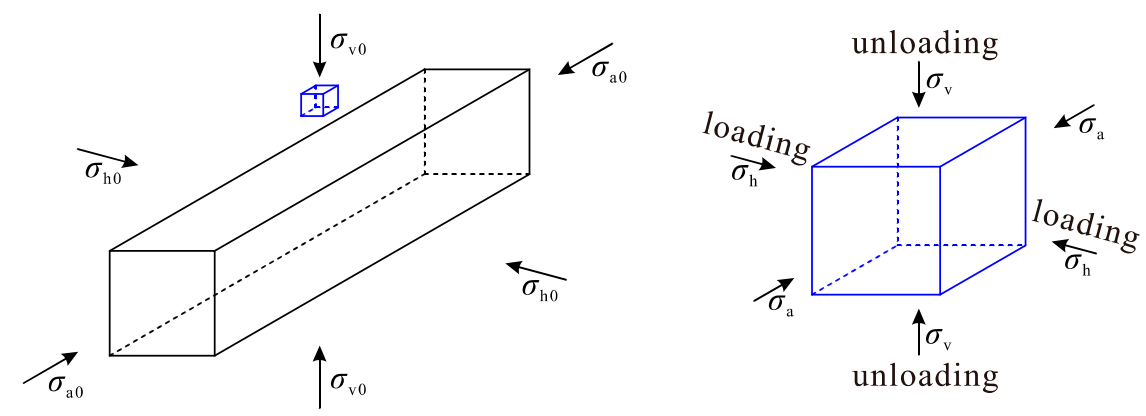

Figure 1. A rectangular tunnel and the in-situ stresses.

Because the failure mode of the surrounding rock in a deep tunnel is mainly shear failure caused by radial unloading, and tensile failure occurs in only the shallow part of the surrounding rock, this section discusses only shear failure (tensile failure is considered in the numerical simulation below). The M-C yield criterion $f$, which is widely used in engineering [28,29], and the nonassociated plastic flow rule are used for the analysis (compression and contraction are considered positive herein).

$$
\begin{gathered}
f=\sigma_{1}-\sigma_{3} N_{\varphi}-2 c \sqrt{N_{\varphi}}=0 \\
g=\sigma_{1}-\sigma_{3} N_{\psi} \\
\Delta \varepsilon_{i}^{\mathrm{p}}=\lambda \frac{\partial g}{\partial \sigma_{i}}, i=1,2,3
\end{gathered}
$$

where $\Delta \varepsilon_{1}^{\mathrm{p}}, \Delta \varepsilon_{2}^{\mathrm{p}}$ and $\Delta \varepsilon_{3}^{\mathrm{p}}$ are the maximum, intermediate and minimum plastic principal strain increments, respectively, $c$ is the cohesion, $\psi$ is the dilation angle, $N_{\alpha}=(1+\sin (\alpha)) /(1-\sin (\alpha))$ is a transformation function, $g$ is a plastic potential function, and $\lambda$ is a constant that can be determined based on the consistency condition.

\subsection{When $\sigma_{a}$ is $\sigma_{1}$ or $\sigma_{3}$ at the Initial Yield}

In the case of a large difference between $\sigma_{\mathrm{a} 0}$ and the in-plane in-situ stress, $\sigma_{\mathrm{a}}$ will be $\sigma_{1}$ or $\sigma_{3}$ at the initial yield of the surrounding rock [8,9]. According to Equations (1) and (2), $\sigma_{\mathrm{a}}$ will control the failure of the surrounding rock and change the directions of the plastic flow (the axial plastic principal strain increment $\Delta \varepsilon_{\mathrm{a}}^{\mathrm{p}}$ becomes $\Delta \varepsilon_{1}^{\mathrm{p}}$ or $\Delta \varepsilon_{3}^{\mathrm{p}}$ ).

Strain softening leads to degradation of the surrounding rock and contraction of the yield surface, which amplifies the effect of $\sigma_{\mathrm{a} 0}$. In a strain softening model, the strength parameters are usually defined as functions of the plastic shear strain $\gamma^{\mathrm{p}}$, but the definitions of $\gamma^{\mathrm{p}}$ are not standardized. $\gamma^{\mathrm{p}}$ is commonly defined as the difference between the maximum plastic principal strain $\varepsilon_{1}^{\mathrm{p}}$ and minimum plastic principal strain $\varepsilon_{3}^{\mathrm{p}}$ [30], and its incremental form $\Delta \gamma^{\mathrm{p}}$ is usually used in calculations:

$$
\Delta \gamma^{\mathrm{p}}=\Delta \varepsilon_{1}^{\mathrm{p}}-\Delta \varepsilon_{3}^{\mathrm{p}}
$$

According to Equations (2) and (3), $\Delta \gamma^{\mathrm{p}}$ can be written as:

$$
\Delta \gamma^{\mathrm{p}}=\left(1+N_{\psi}\right) \lambda
$$

When considering dilatancy, $N_{\psi}>1$, inducing an increase in $\Delta \gamma^{\mathrm{p}}$. This accelerates the strain softening, thus further amplifying the effect of $\sigma_{\mathrm{a} 0}$.

\subsection{When $\sigma_{a}$ Is $\sigma_{2}$ at the Initial Yield}

As shown in Figure 2, if the strain softening is not considered, $\sigma_{\mathrm{a} 0}$ will neither affect the failure nor the plastic flow of the surrounding rock (according to Equation (2), the whole post-peak process is 
represented by 2D plastic flow controlled by $\sigma_{\mathrm{h}}\left(\sigma_{1}\right)$ and $\sigma_{\mathrm{v}}\left(\sigma_{3}\right)$, as shown in Figure 3); thus, $\sigma_{\mathrm{a} 0}$ will not affect the calculation results.

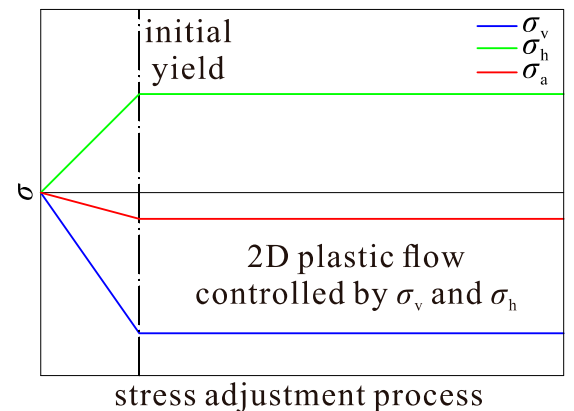

(a)

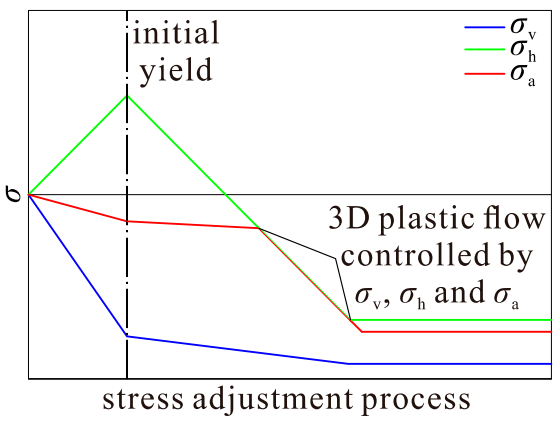

(b)

Figure 2. Stress adjustment and plastic flow of a microunit at the middle of the tunnel roof: (a) perfectly elastoplastic model and (b) considering strain softening.

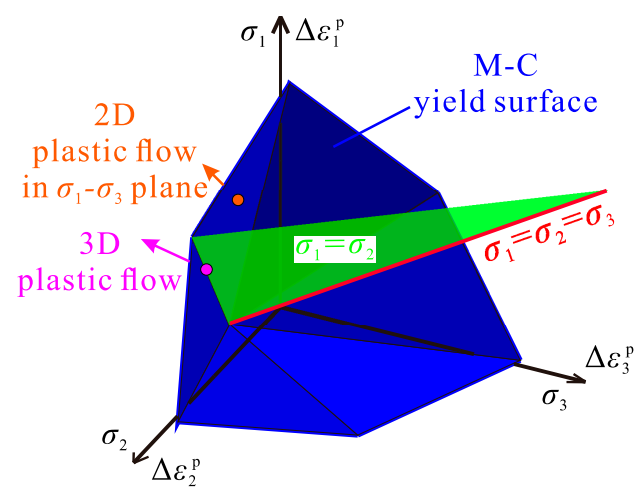

Figure 3. 2D plastic flow and 3D plastic flow.

When considering strain softening, $\sigma_{\mathrm{h}}\left(\sigma_{1}\right)$ rapidly decreases in the post-peak stage, and its curve may intersect with the curve of $\sigma_{\mathrm{a}}$, causing $\sigma_{\mathrm{a}}=\sigma_{\mathrm{h}}>\sigma_{\mathrm{v}}\left(\sigma_{1}=\sigma_{2}>\sigma_{3}\right)$, which will lead to a 3D plastic flow along an edge of the yield surface [31], as shown in Figure 3. The closer $\sigma_{\mathrm{a}}$ is to $\sigma_{\mathrm{h}}$ at the initial yield, the more likely this phenomenon will occur, the earlier it will occur, and the longer it will last. Substituting $\sigma_{\mathrm{a}}, \sigma_{\mathrm{h}}$ and $\sigma_{\mathrm{v}}$ into Equations (1) and (2), the M-C yield criterion $f$ and the nonassociated plastic flow rule become:

$$
\begin{aligned}
& f_{1}=\sigma_{\mathrm{a}}-\sigma_{\mathrm{v}} N_{\varphi}-2 c \sqrt{N_{\varphi}}=0 \\
& f_{2}=\sigma_{\mathrm{h}}-\sigma_{\mathrm{v}} N_{\varphi}-2 c \sqrt{N_{\varphi}}=0 \\
& g_{1}=\sigma_{\mathrm{a}}-\sigma_{\mathrm{v}} N_{\psi} \\
& g_{2}=\sigma_{\mathrm{h}}-\sigma_{\mathrm{v}} N_{\psi} \\
& \Delta \varepsilon_{j}^{\mathrm{p}}=\lambda_{1} \frac{\partial g_{1}}{\partial \sigma_{j}}+\lambda_{2} \frac{\partial g_{2}}{\partial \sigma_{j}}, j=\mathrm{a}, \mathrm{h}, \mathrm{v}
\end{aligned}
$$

where $f_{1}$ and $g_{1}$ are the yield criterion and plastic potential function of the $\sigma_{\mathrm{a}}-\sigma_{\mathrm{v}}$ plane, $f_{2}$ and $g_{2}$ are the yield criterion and plastic potential function of the $\sigma_{\mathrm{h}}-\sigma_{\mathrm{v}}$ plane, $\lambda_{1}$ and $\lambda_{2}$ are the constants corresponding to $f_{1}$ and $g_{1}$ and $f_{2}$ and $g_{2}$, respectively, and can be determined based on the consistency condition.

According to Equations (5) and (6), when considering strain softening, $\sigma_{\mathrm{a}}$ will affect the calculation results. This is further discussed by analyzing the vertical, lateral and axial plastic principal strain increments $\Delta \varepsilon_{\mathrm{v}}^{\mathrm{p}}, \Delta \varepsilon_{\mathrm{h}}^{\mathrm{p}}$ and $\Delta \varepsilon_{\mathrm{a}}^{\mathrm{p}}$ of the microunit at the middle of the roof, and the dilatancy is also considered, as shown in Figure 4. 


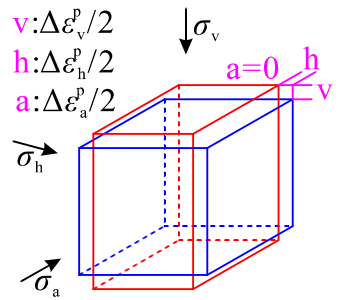

(a)

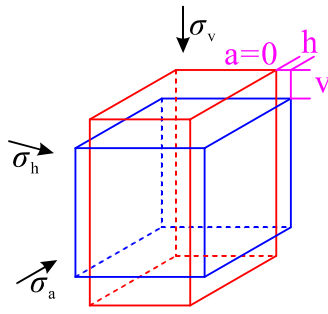

(b)

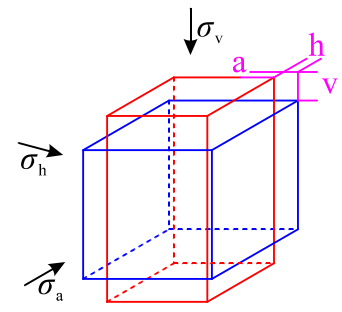

(c)

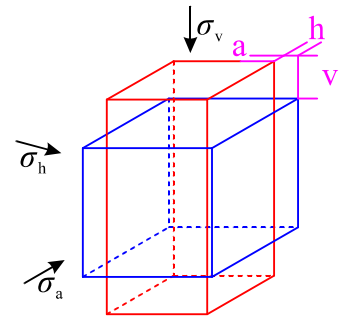

(d)

Figure 4. Plastic principal strain increments of the microunit at the middle of the tunnel roof: (a) perfectly elastoplastic model, (b) considering only dilatancy, (c) considering only strain softening, and (d) considering both strain softening and dilatancy.

According to Figure 4, under the condition that $\sigma_{\mathrm{a}}$ is $\sigma_{2}$ at the initial yield of the surrounding rock, whether consider the strain softening or dilatancy induces the plastic principal strain increments different. The vertical plastic principal strain $\varepsilon_{\mathrm{v}}^{\mathrm{p}}$ is the main component of the roof subsidence (the plastic deformation is a main component of the deformation of the surrounding rock of a deep tunnel), and its increment $\Delta \varepsilon_{\mathrm{v}}^{\mathrm{p}}$ is analyzed below. In addition, the sign represents only contraction or extension, so the absolute values are taken for the following analysis.

For the perfectly elastoplastic model, the whole post-peak process is represented by 2D plastic flow controlled by $\sigma_{\mathrm{h}}$ and $\sigma_{\mathrm{v}}$. In this case, $\psi=0, N_{\psi}=1$, and the following can be derived from Equation (2):

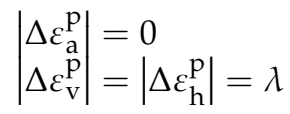

According to Equation (7), $\sigma_{\mathrm{a}}$ has no effect on the results.

When considering only dilatancy, the whole post-peak process is represented by 2D plastic flow controlled by $\sigma_{\mathrm{h}}$ and $\sigma_{\mathrm{v}}$. In this case, $\psi>0, N_{\psi}>1$, and the following can be derived from Equation (2):

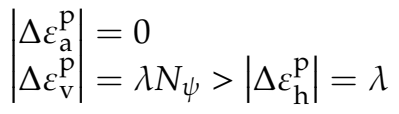

A comparison of Equations (8) and (7) shows that $\Delta \varepsilon_{\mathrm{v}}^{\mathrm{p}}$ increases when considering dilatancy. Additionally, $\sigma_{\mathrm{a}}$ still has no effect on the results.

When considering only strain softening, the whole post-peak process is represented by 3D plastic flow controlled by $\sigma_{\mathrm{a}}, \sigma_{\mathrm{h}}$ and $\sigma_{\mathrm{v}}$. In this case, $\psi=0, N_{\psi}=1$, and the following can be derived from Equation (6):

$$
\left|\Delta \varepsilon_{\mathrm{v}}^{\mathrm{p}}\right|=\left|\Delta \varepsilon_{\mathrm{a}}^{\mathrm{p}}\right|+\left|\Delta \varepsilon_{\mathrm{h}}^{\mathrm{p}}\right|=\lambda_{1}+\lambda_{2}
$$

According to Equation (9), $\Delta \varepsilon_{\mathrm{v}}^{\mathrm{p}}$ increases when considering $\sigma_{\mathrm{a}}$.

When considering both strain softening and dilatancy, the whole post-peak process is represented by $3 \mathrm{D}$ plastic flow controlled by $\sigma_{\mathrm{a}}, \sigma_{\mathrm{h}}$ and $\sigma_{\mathrm{v}}$. In this case, $\psi>0, N_{\psi}>1$, and the following can be derived from Equation (6):

$$
\left|\Delta \varepsilon_{\mathrm{v}}^{\mathrm{p}}\right|=\left(\left|\Delta \varepsilon_{\mathrm{a}}^{\mathrm{p}}\right|+\left|\Delta \varepsilon_{\mathrm{h}}^{\mathrm{p}}\right|\right) N_{\psi}=\left(\lambda_{1}+\lambda_{2}\right) N_{\psi}
$$

A comparison of Equations (10) and (9) shows that $\Delta \varepsilon_{\mathrm{v}}^{\mathrm{p}}$ further increases when considering $\sigma_{\mathrm{a}}$.

In addition, when considering both strain softening and dilatancy, the following can be derived from Equations (4) and (6):

$$
\Delta \gamma^{\mathrm{p}}=\left(1+N_{\psi}\right)\left(\lambda_{1}+\lambda_{2}\right)
$$

Equation (11) indicates that considering $\sigma_{\mathrm{a}}$ will increase $\Delta \gamma^{\mathrm{P}}$ and accelerate the strain softening process. 
In summary, if $\sigma_{\mathrm{a}}$ is $\sigma_{1}$ or $\sigma_{3}$ at the initial yield of the surrounding rock, $\sigma_{\mathrm{a}}$ will control the failure of the surrounding rock and change the directions of the plastic flow, and the effect of $\sigma_{\mathrm{a}}$ will be amplified by considering strain softening. If $\sigma_{\mathrm{a}}$ is $\sigma_{2}$, without considering strain softening, $\sigma_{\mathrm{a}}$ has no effect on the results; when considering strain softening, $3 \mathrm{D}$ plastic flow may occur, and considering $\sigma_{\mathrm{a}}$ will increase the deformation of the surrounding rock and accelerate the strain softening process. The effect of $\sigma_{\mathrm{a}}$ will be further amplified by considering dilatancy.

However, the above analysis discusses only the plastic principal strain increments of the microunit at the middle of the roof and does not indicate under what conditions $\sigma_{\mathrm{a}}$ will become $\sigma_{1}, \sigma_{2}$ or $\sigma_{3}$ at the initial yield and under what conditions 3D plastic flow will occur. Additionally, the variations in $c$ and $\psi$ are not considered. A numerical simulation is adopted below to verify the theoretical analysis results and further analyze.

\section{Numerical Simulation}

\subsection{Constitutive Model Development}

FLAC $^{3 \mathrm{D}}$ includes a built-in strain softening model [32], but the effect of the confining stress on the dilation angle cannot be considered. The softening parameter is defined as the square root of the second invariant of the plastic deviatoric strain instead of the plastic shear strain. Material parameters can be defined by only piecewise linear functions of the softening parameter. Therefore, a new constitutive model is developed herein with $\mathrm{C}++$ to accurately consider the strain softening and dilatancy of the surrounding rock.

There have been many strain softening models and dilation angle models presented in previous studies, but few have presented both strain softening and dilation models at the same time. Based on the triaxial test data of many sedimentary rocks, Pourhosseini and Shabanimashcool [30] presented two such models at the same time and pointed out that during the strain softening process, only the cohesion $c$ degrades, whereas the friction angle $\varphi$ remains constant.

$$
\begin{aligned}
& c=c_{0}\left(1-\frac{\tanh \left(100 \gamma^{\mathrm{p}}\right)}{\tanh (10)}+0.001\right)^{A} \\
& \psi=\psi_{0}\left(1-\frac{\tanh \left(100 \gamma^{\mathrm{p}}\right)}{\tanh (10)}+0.001\right)^{B} \\
& \psi_{0}=C \ln \left(\frac{\varphi \sigma_{c}}{\sigma_{3}+0.1}\right)-D
\end{aligned}
$$

where $c_{0}$ and $\psi_{0}$ are the peak cohesion and dilation angle, respectively, $\sigma_{\mathrm{c}}$ is the uniaxial compressive strength, and $a, b, A$, and $B$ are fitting parameters that depend on the rock type $(A=0.340, B=0.125$, $C=6.794$, and $D=15.308$ for mudstone [30]).

According to the variations in the parameters in Equations (12) and (13), combined with the M-C yield criterion and the nonassociated plastic flow rule, a constitutive model considering both strain softening and dilatancy is developed. Its function is to calculate all the stress components $\sigma_{\text {all }}^{i+1}$ of the $i+1$ cycle using all the stress components $\sigma_{\text {all }}^{i}$ and all the strain increments $\Delta \varepsilon_{\text {all }}$ of the $i$ cycle and update the related material parameters, the M-C yield criterion and the plastic potential function. The main calculation steps are shown in Figure 5. Firstly, calculate the elastic stress increment guess $\Delta \sigma_{\text {all }}^{\mathrm{e}}$ (assume that $\Delta \varepsilon_{\text {all }}$ is elastic, so it is called guess) by generalized Hooke's law using $\Delta \varepsilon_{\text {all }}$. Secondly, calculate the elastic stress guess $\sigma_{\text {all }}^{\mathrm{e}}$ as the sum of $\sigma_{\text {all }}^{i}$ and $\Delta \sigma_{\text {all }}^{\mathrm{e}}$. Finally, determine whether the material is yield using $\sigma_{\text {all }}^{\mathrm{e}}$. If the material is yield, $\sigma_{\text {all }}^{i+1}$ will be output after stress correction. If the material is not yield, $\sigma_{\text {all }}^{i+1}$ will be output directly. The cohesion $c$ is updated by the plastic shear stain $\gamma^{\mathrm{p}}$ to achieve strain softening, then the yield criterion $f$ is updated, which will affect the yield determination and stress correction. The strain softening and dilatancy switches can both be closed (corresponding to the perfectly elastoplastic model, identical to the built-in M-C model), both be opened, or be opened any 
one of them. The method described by Itasca Inc. [32] is used to verify the constitutive model, and the variations in $c$ and $\psi$ are accurately consistent with Equations (12) and (13).

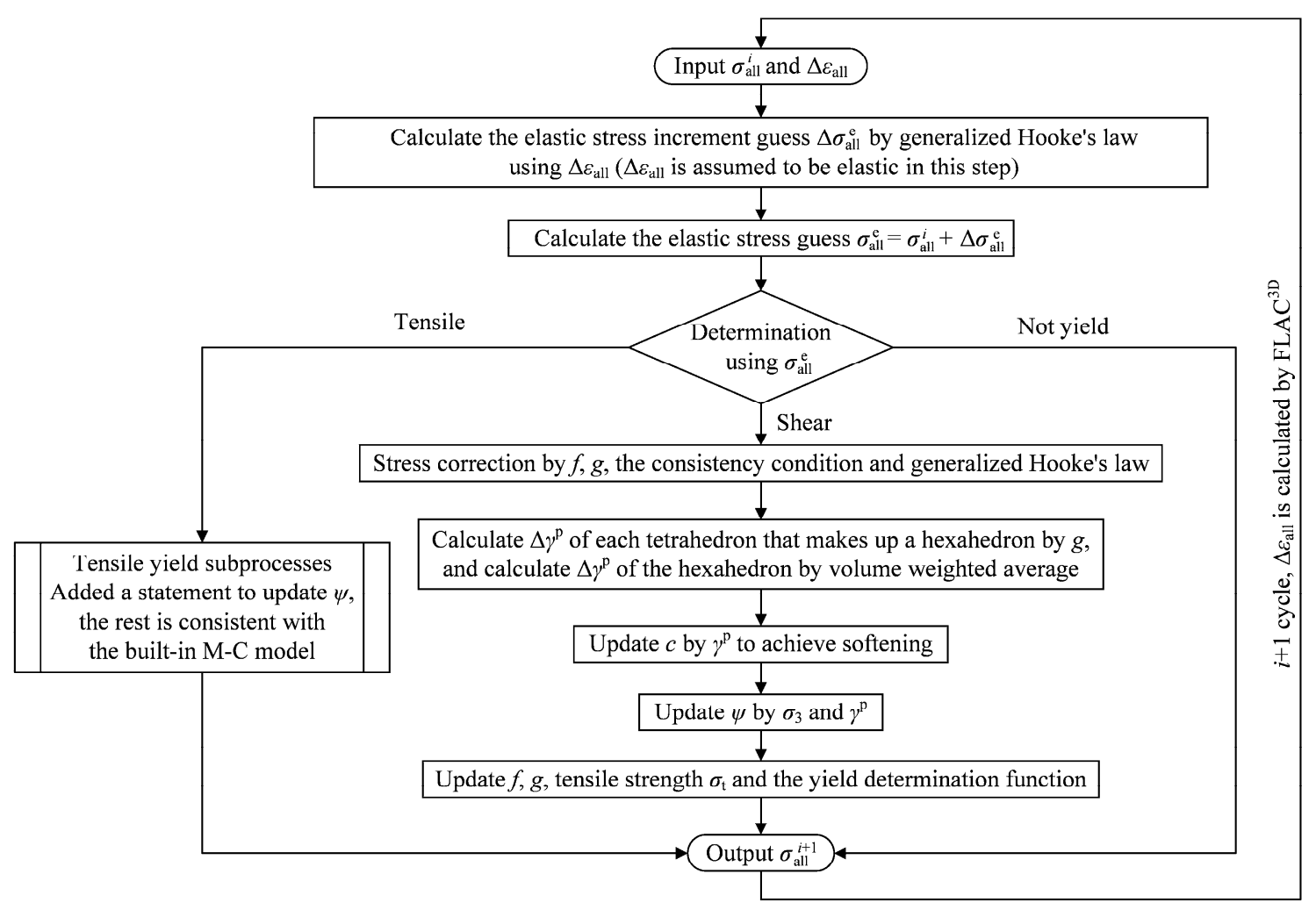

Figure 5. Main calculation steps of the constitutive model.

\subsection{Numerical Model and Schemes}

To exclude other influencing factors and considering that the vertical in-situ stress is stable and that the horizontal in-situ stress does not vary considerably [27], the following schemes are adopted: the excavation depth is set to $1000 \mathrm{~m}\left(\sigma_{\mathrm{v} 0}=25 \mathrm{MPa}\right)$, and the surrounding rock is a homogeneous mudstone, with $c_{0}=6.37 \mathrm{MPa}$ and $\varphi=25^{\circ}\left(\sigma_{\mathrm{c}}=20 \mathrm{MPa}\right)$. The perfectly elastoplastic model, considering only dilatancy, considering only strain softening and considering both strain softening and dilatancy are the four investigated conditions, $\sigma_{\mathrm{h} 0} / \sigma_{\mathrm{v} 0}=0.50,0.75,1.00,1.25$ and 1.50 are the five investigated lateral in-situ stress ratios, and $\sigma_{\mathrm{a} 0} / \sigma_{\mathrm{v} 0}=0.5,0.75,1.00,1.25$ and 1.50 are the five investigated axial in-situ stress ratios, for a total of 100 schemes. The Initial command [32] is used to generate the in-situ stress. The compressive stress is negative in the model, but for the convenience of analysis, the compressive stress is positive herein. As shown in Figure 6, the cross-section of the rectangular tunnel is set to $3 \mathrm{~m} \times 3 \mathrm{~m}$ (a common cross-section in coal mines [1]), the model thickness is set to $5 \mathrm{~m}$ (although it is a planar problem, the axial plastic flow can be simulated more precisely in this way), the model boundaries are $30 \mathrm{~m}$ away from the excavation boundaries (10 times the tunnel dimension to reduce the error caused by the artificial boundaries), and all the model boundaries are fixed in the normal directions (if the artificial boundaries are far enough, the results of displacement boundary conditions and stress boundary conditions are almost the same, and the former is selected herein). The model has a total of 41,210 grids and 49,172 nodes, and nearly uniform mesh generation is adopted in the potential plastic zone to reduce the influence caused by the strain localization problem [33]. When the current maximum unbalanced force in the model is less than $10^{-5}$ times (recommended ratio in the manual [32]) the maximum unbalanced force just after the excavation, the model is considered to be in equilibrium. Because the deformation and failure mechanism of the roof, floor and two sidewalls of a deep tunnel are similar, the roof as taken as an example to analyze the effect of $\sigma_{\mathrm{a} 0}$. 


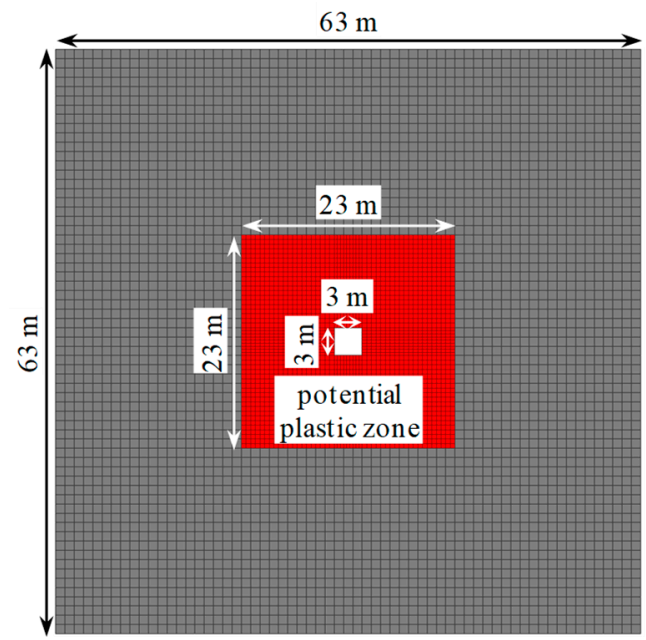

Figure 6. Model size and mesh.

\subsection{Analysis of the Roof Subsidence and Plastic Zone Depth}

The precision of the maximum plastic zone depth is restricted by the mesh size, so this index is not adopted, and the following statistical method is used to characterize the plastic zone depth to improve the precision: the maximum depth $d$ of the plastic zone of the roof and the corresponding grid number $n_{d}$ are recorded; the roof width $w$ and the corresponding grid number $n_{w}$ are recorded; the total number $n$ of plastic zone grids within the $d \times w$ area is counted; the plastic zone depth is calculated from $d\left(n / n_{d} n_{w}\right)$. The roof subsidence is directly read in FLAC ${ }^{3 \mathrm{D}}$. The results are shown in Figures 7-10.

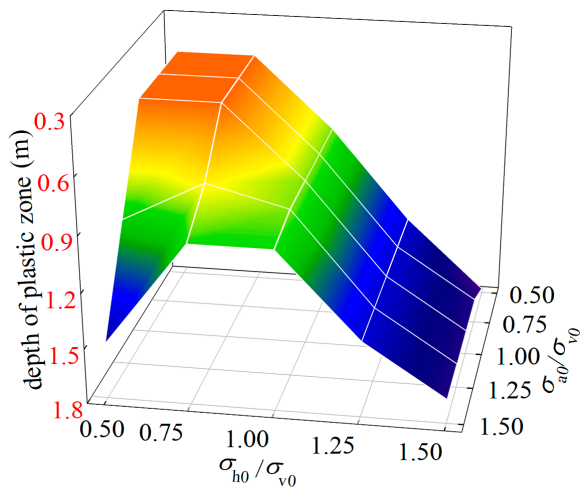

(a)

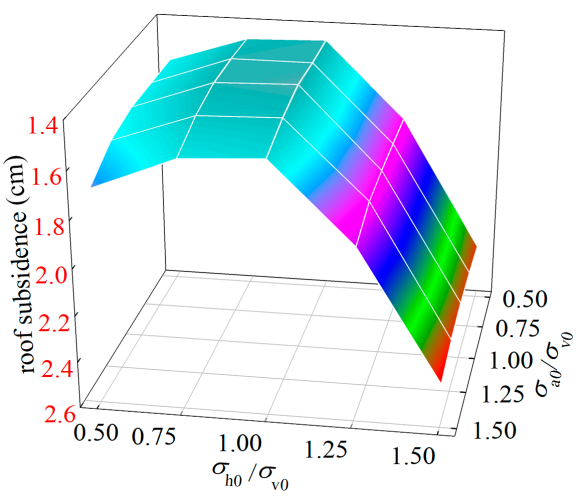

(b)

Figure 7. Results of the perfectly elastoplastic model: (a) roof plastic zone depth and (b) roof subsidence.

For the perfectly elastoplastic model, when $\sigma_{\mathrm{h} 0} / \sigma_{\mathrm{v} 0} \leq 0.75$ and $\sigma_{\mathrm{a} 0} / \sigma_{\mathrm{v} 0}>1.00$, the plastic zone depth increases rapidly with an increase in $\sigma_{\mathrm{a} 0}$, indicating that $\sigma_{\mathrm{a}}$ is $\sigma_{1}$ at the initial yield and controls the failure of the surrounding rock; when $\sigma_{\mathrm{h} 0} / \sigma_{\mathrm{v} 0}=1.50$ and $\sigma_{\mathrm{a} 0} / \sigma_{\mathrm{v} 0}<1.00$, a decrease in $\sigma_{\mathrm{a} 0}$ slightly increases the plastic zone depth, indicating that $\sigma_{\mathrm{a}}$ is $\sigma_{3}$ at the initial yield and also controls the failure, which is consistent with the conclusion of Section 2.2. An increase in $\sigma_{\mathrm{a} 0}$ slightly increases the roof subsidence only when $\sigma_{\mathrm{h} 0} / \sigma_{\mathrm{v} 0}=0.5$ and $\sigma_{\mathrm{a} 0} / \sigma_{\mathrm{v} 0}>1.00$; the other schemes have little effect. In addition, the plastic zone depths are shallow, and the maximum plastic zone depth is only $1.78 \mathrm{~m}$; the roof subsidence results are very small, and the maximum roof subsidence is only $2.41 \mathrm{~cm}$, which is inconsistent with the observed severe failure and large deformation of the surrounding rock of deep tunnels [2,34]. 


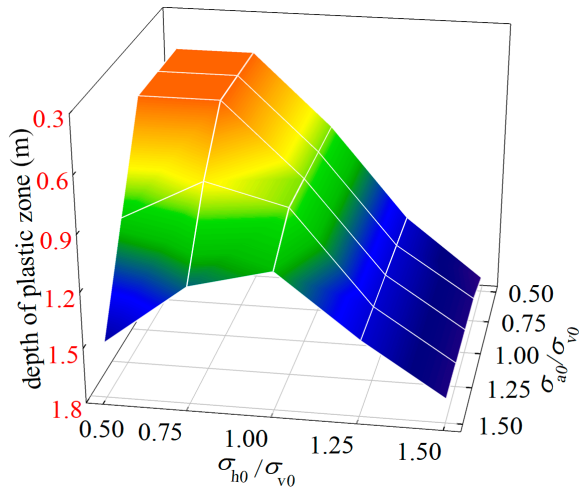

(a)

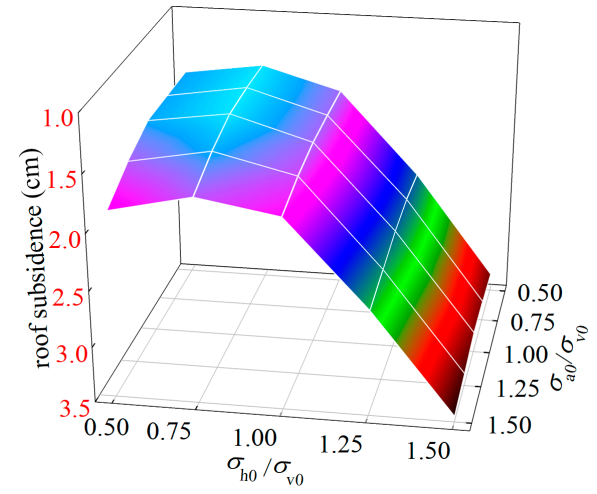

(b)

Figure 8. Results considering only dilatancy: (a) roof plastic zone depth, and (b) roof subsidence.

When considering only dilatancy, the variations in the plastic zone depth and roof subsidence are similar to those of the perfectly elastoplastic model, but the effect of $\sigma_{\mathrm{a} 0}$ on the roof subsidence is more obvious, which is consistent with the conclusions of Section 2.2, Figure $4 \mathrm{~b}$ and Equation (8). In addition, the plastic zone depths exhibit little change compared with that of the perfectly elastoplastic model, with a maximum of $1.72 \mathrm{~m}$; the roof subsidence results increase compared with that of the perfectly elastoplastic model, but the results are still very small, with a maximum of $3.45 \mathrm{~cm}$.

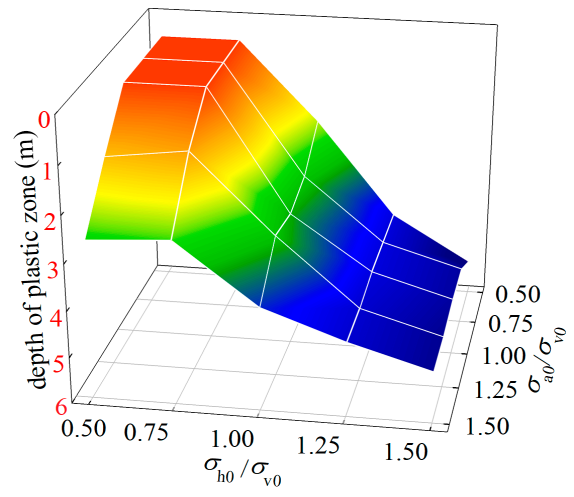

(a)



(b)

Figure 9. Results considering only strain softening: (a) roof plastic zone depth and (b) roof subsidence.

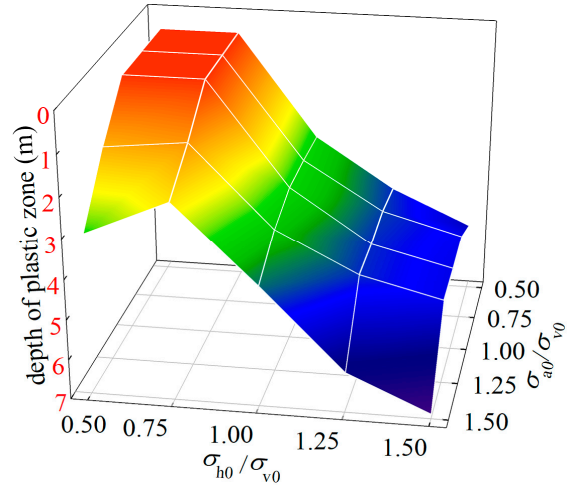

(a)



(b)

Figure 10. Results considering both strain softening and dilatancy: (a) roof plastic zone depth and (b) roof subsidence. 
When considering only strain softening, except for the magnitude of values, the variation in the plastic zone depth is similar to that under the above two conditions. The effect of $\sigma_{\mathrm{a} 0}$ on roof subsidence is more significant than that under the above two conditions. When $\sigma_{\mathrm{h} 0} / \sigma_{\mathrm{v} 0} \geq 1.00$, an increase in $\sigma_{\mathrm{a} 0}$ significantly increases the roof subsidence, which is caused by the 3D plastic flow partly controlled by $\sigma_{\mathrm{a}}$, consistent with the conclusions of Section 2.2, Figure $4 \mathrm{c}$ and Equation (9). In addition, the plastic zone depth and roof subsidence results increase significantly compared with those under the above two conditions, with maxima of $5.28 \mathrm{~m}$ and $16.92 \mathrm{~cm}$, respectively.

When considering both strain softening and dilatancy, except for the magnitude of values, the variation in the plastic zone depth is similar to those under the above three conditions. The effect of $\sigma_{\mathrm{a} 0}$ on roof subsidence is more significant than that considering only strain softening. When $\sigma_{\mathrm{h} 0} / \sigma_{\mathrm{v} 0} \geq 1.00$, an increase in $\sigma_{\mathrm{a} 0}$ significantly increases the roof subsidence, and the larger $\sigma_{\mathrm{h} 0} / \sigma_{\mathrm{v} 0}$ and $\sigma_{\mathrm{a} 0} / \sigma_{\mathrm{v} 0}$ are, the more significant the effect, which is consistent with the conclusions of Section 2.2, Figure $4 \mathrm{~d}$ and Equation (10). In addition, the plastic zone depth and roof subsidence results further increase compared with those considering only strain softening, with maxima of $6.89 \mathrm{~m}$ and $42.91 \mathrm{~cm}$, respectively, which is more consistent with reality $[2,34]$.

\subsection{Analysis of the Stress Adjustment Process}

To prove the existence of 3D plastic flow and analyze the conditions under which it occurs, considering the objective post-peak behavior of the surrounding rock, namely, its strain softening and dilatancy, the stress adjustment process is analyzed via numerical simulation. The principal stresses at the middle of the roof with a depth of $1.25 \mathrm{~m}$ (where the radial strain is large) are monitored. For the nine schemes where $\sigma_{\mathrm{h} 0} / \sigma_{\mathrm{v} 0}=0.50,1.00$ and 1.50 and $\sigma_{\mathrm{a} 0} / \sigma_{\mathrm{v} 0}=0.50,1.00$ and 1.50 , the monitoring results are shown in Figure 11. Since the criterion of model equilibrium is that the maximum unbalanced force is less than a specific ratio, the calculation steps are different when each scheme reaches equilibrium (the nine schemes take 3191-5201 steps to reach equilibrium). The first 1000 steps during which the principal stresses vary dramatically are selected for analysis. FLAC ${ }^{3 \mathrm{D}}$ adopts the dynamic relaxation method [32]. Nodes of a model move under the action of the unbalanced force and are damped in proportion to the magnitude of the unbalanced force, which dissipates the excess energy and tends to equilibrate the model. In the elastic stage, the nodes oscillate under the action of the unbalanced force and damping, which leads to the drastic variations of the strain components of zones of the model, and then leads to the large wavy patterns of the stress curves of the zones. In the plastic stage, the stresses of the zones are controlled by the yield criterion, resulting in the stress curves wave only slightly. If the zone at the measuring point does not yield, as shown in Figure 11a,b, the zone is in the elastic stage during the whole simulation process, thus the stress curves of the zone wave significantly. The built-in Fish keyword is adopted to monitor the plastic state of the measuring point. The stress curves are used to identify the plastic flow regime. If $\sigma_{\mathrm{a}}=\sigma_{\mathrm{h}}>\sigma_{\mathrm{v}}$, 3D plastic flow occurs, otherwise 2D plastic flow occurs. 


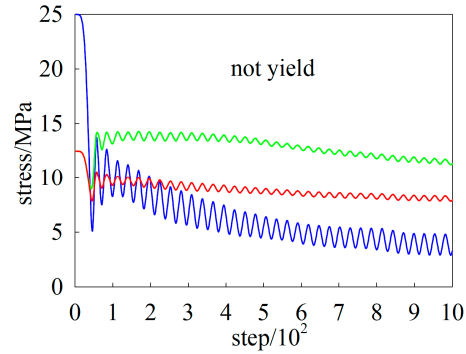

(a)



(d)

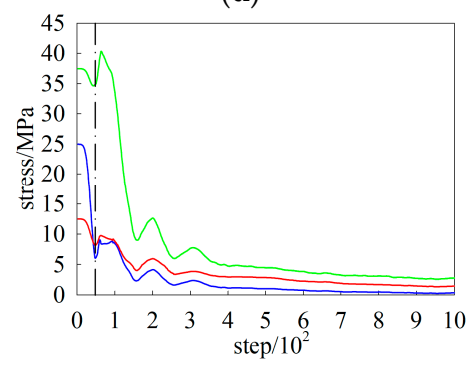

(g)

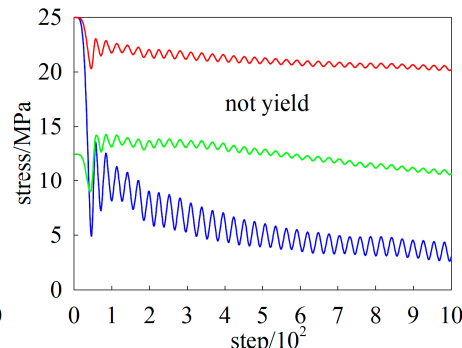

(b)

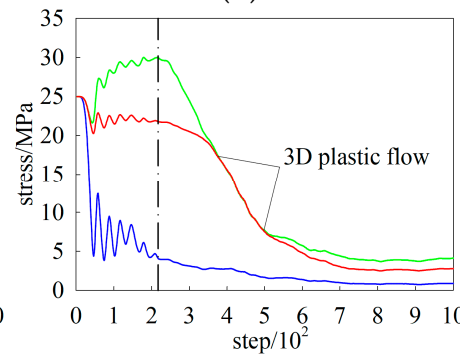

(e)

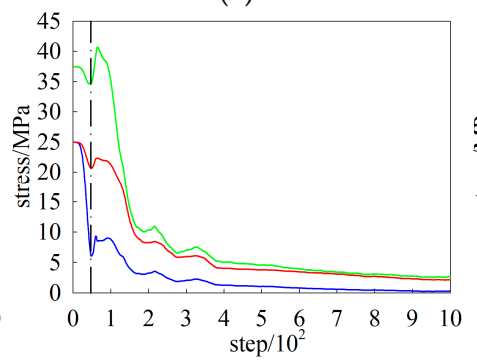

(h)

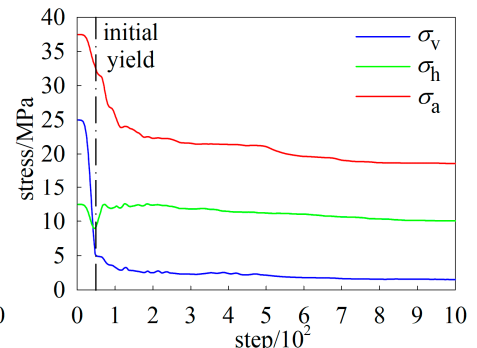

(c)

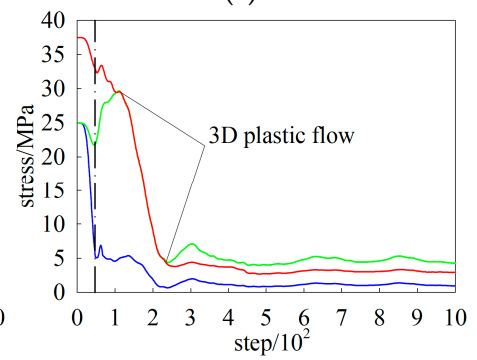

(f)

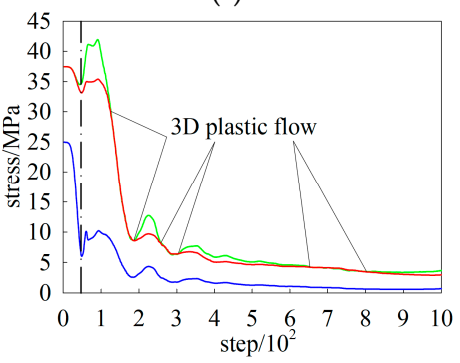

(i)

Figure 11. Monitoring results of the principal stresses: (a) $\sigma_{\mathrm{h} 0} / \sigma_{\mathrm{v} 0}=0.50, \sigma_{\mathrm{a} 0} / \sigma_{\mathrm{v} 0}=0.50,(\mathbf{b}) \sigma_{\mathrm{h} 0} / \sigma_{\mathrm{v} 0}$ $=0.50, \sigma_{\mathrm{a} 0} / \sigma_{\mathrm{v} 0}=1.00,(\mathbf{c}) \sigma_{\mathrm{h} 0} / \sigma_{\mathrm{v} 0}=0.50, \sigma_{\mathrm{a} 0} / \sigma_{\mathrm{v} 0}=1.50,(\mathbf{d}) \sigma_{\mathrm{h} 0} / \sigma_{\mathrm{v} 0}=1.00, \sigma_{\mathrm{a} 0} / \sigma_{\mathrm{v} 0}=0.50,(\mathbf{e}) \sigma_{\mathrm{h} 0} / \sigma_{\mathrm{v} 0}=$ $1.00, \sigma_{\mathrm{a} 0} / \sigma_{\mathrm{v} 0}=1.00,(\mathbf{f}) \sigma_{\mathrm{h} 0} / \sigma_{\mathrm{v} 0}=1.00, \sigma_{\mathrm{a} 0} / \sigma_{\mathrm{v} 0}=1.50,(\mathbf{g}) \sigma_{\mathrm{h} 0} / \sigma_{\mathrm{v} 0}=1.50, \sigma_{\mathrm{a} 0} / \sigma_{\mathrm{v} 0}=0.50,(\mathbf{h}) \sigma_{\mathrm{h} 0} / \sigma_{\mathrm{v} 0}=1.50$, $\sigma_{\mathrm{a} 0} / \sigma_{\mathrm{v} 0}=1.00$, and (i) $\sigma_{\mathrm{h} 0} / \sigma_{\mathrm{v} 0}=1.50, \sigma_{\mathrm{a} 0} / \sigma_{\mathrm{v} 0}=1.50$.

At the middle of the roof, $\sigma_{\mathrm{v}}$ is $\sigma_{\mathrm{r}}$, and $\sigma_{\mathrm{h}}$ is $\sigma_{\mathrm{t}}$. According to Figure $11, \sigma_{\mathrm{a}}$ is generally not $\sigma_{3}$ at the initial yield of the surrounding rock. When $\sigma_{\mathrm{a} 0}$ is much lower than $\sigma_{\mathrm{h} 0}, \sigma_{\mathrm{a}}$ is always $\sigma_{2}$ in the yield stage, and $\sigma_{\mathrm{a} 0}$ has little effect on the results. When $\sigma_{\mathrm{a} 0}$ is close to $\sigma_{\mathrm{h} 0}$, according to Figure $11 \mathrm{e}, \mathrm{i}, \sigma_{\mathrm{a}}$ is $\sigma_{2}$ at the initial yield, but $\sigma_{\mathrm{a}}=\sigma_{\mathrm{h}}>\sigma_{\mathrm{v}}\left(\sigma_{1}=\sigma_{2}>\sigma_{3}\right)$ later, resulting in 3D plastic flow, and combining this finding with Figure $10 \mathrm{~b}$, it can be seen that the roof subsidence suddenly increases. When $\sigma_{\mathrm{a} 0}$ is significantly greater than $\sigma_{\mathrm{h} 0}$ (1.5 times), according to Figure $11 \mathrm{f}, \sigma_{\mathrm{a}}$ is $\sigma_{1}$ at the initial yield, but $\sigma_{\mathrm{a}}=\sigma_{\mathrm{h}}$ $>\sigma_{\mathrm{v}}$ later, resulting in 3D plastic flow, and combining this finding with Figure 10b, it can be seen that the roof subsidence further increases. When $\sigma_{\mathrm{a} 0}$ is much larger than $\sigma_{\mathrm{h} 0}$ (three times), $\sigma_{\mathrm{a}}$ is always $\sigma_{1}$ in the yield stage, 3D plastic flow no longer occurs, and the roof subsidence remains small; however, according to the field monitoring data of the in-situ stresses and the surrounding rock displacements of many deep tunnels $[27,34]$, such an in-situ stress state rarely exists in deep areas.

\section{Verification via Field Monitoring Data}

To exclude other influencing factors, the effect of $\sigma_{\mathrm{a} 0}$ on the deep tunnel is analyzed under the ideal conditions described above. It is difficult to find the same conditions in reality, but can choose a deep tunnel nearly perpendicularly cross a reverse fault, and by comparing the displacements of the surrounding rock in the higher axial in-situ stress zone near the reverse fault (the axial in-situ stress increases and is higher than the tangential in-situ stress near a reverse fault [35]) with those in the normal zone far from the reverse fault, the results discussed above can be verified. The excavation 
depth of the 020202 rail gateway of the Qingyun coal mine in Shanxi Province, China, is $780 \mathrm{~m}$, the roof is a medium-grained sandstone, the floor is a sandy mudstone, and the sidewall is a coal seam. The gateway is supported by a rock bolting system with a width of $4.5 \mathrm{~m}$ and a height of $4.3 \mathrm{~m}$ and nearly perpendicularly crosses a reverse fault with a dip angle of $54.5^{\circ}$ and a throw of $1.8 \mathrm{~m}$. To avoid the influence of the fracture zone of the reverse fault, the no. 2 measuring station was located $7 \mathrm{~m}$ from the reverse fault, and the no. 1 and no. 3-5 measuring stations were arranged far away from the reverse fault at intervals of $30 \mathrm{~m}$. The displacements of the gateway were monitored, and the displacements 60 $\mathrm{d}$ after excavation are shown in Figure 12.

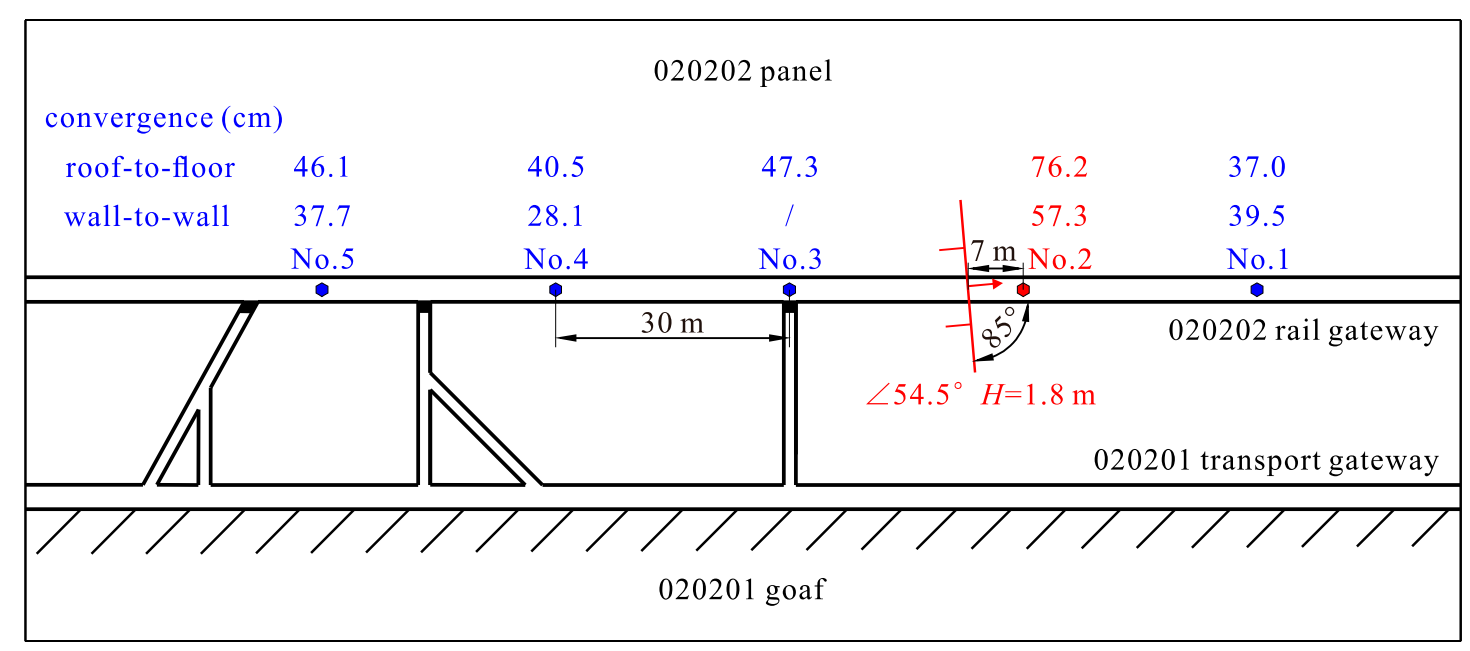

Figure 12. Displacements of the 020202 rail gateway $60 \mathrm{~d}$ after excavation.

According to Figure 12, at the no. 2 measuring station in the higher axial in-situ stress zone, the roof-to-floor convergence is $76.2 \mathrm{~cm}$, and the wall-to-wall convergence is $57.3 \mathrm{~cm}$, significantly larger than those of $37.0-47.3 \mathrm{~cm}$ and $28.1-39.5 \mathrm{~cm}$ in the normal zone, respectively. In addition, when the excavation of the gateway reached the location of the no. 2 measuring station, no abnormality was found in the surrounding rock, but the failure of the surrounding rock at the no. 2 measuring station was significantly more severe than that at the no. 1 and no. 3-5 measuring stations $60 \mathrm{~d}$ after excavation. This observation verifies the results above, namely, considering the objective strain softening and dilatancy, when $\sigma_{\mathrm{a} 0}$ is close to or greater than $\sigma_{\mathrm{t} 0}$, an increase in $\sigma_{\mathrm{a} 0}$ will increase the deformation and failure of the surrounding rock of a deep tunnel. Therefore, the effect of $\sigma_{\mathrm{a} 0}$ and the strain softening and dilatancy of the surrounding rock should be considered in the deformation prediction and support design of a deep tunnel.

\section{Conclusions}

In this study, based on the incremental plastic flow theory, theoretical analysis and numerical simulation are adopted to analyze the effect of the axial in-situ stress $\sigma_{\mathrm{a} 0}$ on the deformation and failure of the surrounding rock of a deep tunnel considering strain softening and dilatancy, and the results are verified via field monitoring data. The following conclusions are obtained:

For the perfectly elastoplastic model, only when the axial stress $\sigma_{\mathrm{a}}$ is $\sigma_{1}$ or $\sigma_{3}$ at the initial yield of the surrounding rock, an increase or decrease in $\sigma_{\mathrm{a} 0}$ intensifies the failure of the surrounding rock; otherwise, $\sigma_{\mathrm{a} 0}$ has little effect on the results. When considering only dilatancy, the effect of $\sigma_{\mathrm{a} 0}$ is similar to that of the perfectly elastoplastic model. When considering only strain softening, compared with the two conditions above, the effect of $\sigma_{\mathrm{a} 0}$ is more significant when $\sigma_{\mathrm{a}}$ is $\sigma_{1}$ or $\sigma_{3}$ at the initial yield, and 3D plastic flow partly controlled by $\sigma_{\mathrm{a}}$ may occur when $\sigma_{\mathrm{a}}$ is $\sigma_{2}$ at the initial yield, which leads to $\sigma_{\mathrm{a} 0}$ also having a significant effect, such that an increase in $\sigma_{\mathrm{a} 0}$ intensifies the deformation and failure of 
the surrounding rock. When considering both strain softening and dilatancy, the effect of $\sigma_{\mathrm{a} 0}$ is more significant than that when considering only strain softening.

When considering both strain softening and dilatancy, $\sigma_{\mathrm{a}}$ is generally not $\sigma_{3}$ at the initial yield. When $\sigma_{\mathrm{a} 0}$ is much lower than the tangential in-situ stress $\sigma_{\mathrm{t} 0}, \sigma_{\mathrm{a}}$ is always $\sigma_{2}$ in the yield stage, and $\sigma_{\mathrm{a} 0}$ has little effect on the results. When $\sigma_{\mathrm{a} 0}$ is close to $\sigma_{\mathrm{t} 0}, \sigma_{\mathrm{a}}$ is $\sigma_{2}$ at the initial yield, but $\sigma_{1}=\sigma_{2}>\sigma_{3}$ later, resulting in 3D plastic flow along an edge of the yield surface, and an increase in $\sigma_{\mathrm{a} 0}$ intensifies the deformation and failure of the surrounding rock. When $\sigma_{\mathrm{a} 0}$ is significantly greater than $\sigma_{\mathrm{t} 0}$ (1.5 times), $\sigma_{\mathrm{a}}$ is $\sigma_{1}$ at the initial yield, but 3D plastic flow also occurs later, and the deformation and failure of the surrounding rock will be further intensified when $\sigma_{\mathrm{a} 0}$ increases.

A deep tunnel is significantly affected by the in-situ stress, and a large post-peak zone forms in the surrounding rock. In the deformation prediction and support design of a deep tunnel, the axial in-situ stress should not be ignored, and the post-peak behavior of the surrounding rock should be accurately considered.

Author Contributions: Conceptualization, K.Y.; methodology, K.Y., Z.L.; software, K.Y., Z.L.; validation, Z.L.; formal analysis, J.Z.; investigation, K.Y., S.D.; resources, J.Z.; data curation, K.Y.; writing—original draft preparation, K.Y.; writing—review and editing, Z.L.; visualization, K.Y.; supervision, Z.L.; project administration, Z.L., J.Z.; funding acquisition, Z.L., J.Z. All authors have read and agreed to the published version of the manuscript.

Funding: This research was funded by National Natural Science Foundation of China, grant numbers 51574174 and 51974319, National Key Research and Development Program of China, grant number 2017 YC0603003.

Acknowledgments: The authors would like to acknowledge anonymous reviewers for their valuable comments.

Conflicts of Interest: The authors declare no conflict of interest.

\section{References}

1. Kang, H.; Wu, Y.; Gao, F.; Lin, J.; Jiang, P. Fracture characteristics in rock bolts in underground coal mine roadways. Int. J. Rock Mech. Min. Sci. 2013, 62, 105-112. [CrossRef]

2. Wang, M.; Zhang, N.; Li, J.; Ma, L.; Fan, P. Computational method of large deformation and its application in deep mining tunnel. Tunn. Undergr. Space Technol. 2015, 50, 47-53. [CrossRef]

3. Tao, M.; Hong, Z.; Peng, K.; Sun, P.; Cao, M.; Du, K. Evaluation of Excavation-Damaged Zone around Underground Tunnels by Theoretical Calculation and Field Test Methods. Energies 2019, 12, 1682. [CrossRef]

4. Yang, S.-Q.; Chen, M.; Jing, H.-W.; Chen, K.-F.; Meng, B. A case study on large deformation failure mechanism of deep soft rock roadway in Xin'An coal mine, China. Eng. Geol. 2017, 217, 89-101. [CrossRef]

5. Zhang, Q.; Zhang, C.; Jiang, B.; Li, N.; Wang, Y. Elastoplastic Coupling Solution of Circular Openings in Strain-Softening Rock Mass Considering Pressure-Dependent Effect. Int. J. Geomech. 2018, 18. [CrossRef]

6. Cui, L.; Zheng, J.-J.; Dong, Y.-K.; Zhang, B.; Wang, A. Prediction of critical strains and critical support pressures for circular tunnel excavated in strain-softening rock mass. Eng. Geol. 2017, 224, 43-61. [CrossRef]

7. Song, L.; Li, H.-Z.; Chan, C.L.; Low, B.K. Reliability analysis of underground excavation in elastic-strain-softening rock mass. Tunn. Undergr. Space Technol. 2016, 60, 66-79. [CrossRef]

8. Lu, A.-Z.; Xu, G.-S.; Sun, F.; Sun, W.-Q. Elasto-plastic analysis of a circular tunnel including the effect of the axial in situ stress. Int. J. Rock Mech. Min. Sci. 2010, 47, 50-59. [CrossRef]

9. Wang, S.; Wu, Z.; Guo, M.; Ge, X. Theoretical solutions of a circular tunnel with the influence of axial in situ stress in elastic-brittle-plastic rock. Tunn. Undergr. Space Technol. 2012, 30, 155-168. [CrossRef]

10. Guan, K.; Zhu, W.; Wei, J.; Liu, X.; Niu, L.; Wang, X. A finite strain numerical procedure for a circular tunnel in strain-softening rock mass with large deformation. Int. J. Rock Mech. Min. Sci. 2018, 112, 266-280. [CrossRef]

11. Alejano, L.R.; Alonso, E. Considerations of the dilatancy angle in rocks and rock masses. Int. J. Rock Mech. Min. Sci. 2005, 42, 481-507. [CrossRef]

12. Cai, M.; Kaiser, P.K.; Tasaka, Y.; Minami, M. Determination of residual strength parameters of jointed rock masses using the GSI system. Int. J. Rock Mech. Min. Sci. 2007, 44, 247-265. [CrossRef]

13. Cai, M.; Kaiser, P.K.; Uno, H.; Tasaka, Y.; Minami, M. Estimation of rock mass deformation modulus and strength of jointed hard rock masses using the GSI system. Int. J. Rock Mech. Min. Sci. 2004, 41, 3-19. [CrossRef] 
14. Hoek, E.; Brown, E.T. Practical estimates of rock mass strength. Int. J. Rock Mech. Min. Sci. 1997, 34, 1165-1186. [CrossRef]

15. Hoek, E.; Diederichs, M.S. Empirical estimation of rock mass modulus. Int. J. Rock Mech. Min. Sci. 2006, 43, 203-215. [CrossRef]

16. Zhao, X.G.; Cai, M.F.; Cai, M. Considerations of rock dilation on modeling failure and deformation of hard rocks: A case study of the mine-by test tunnel in Canada. J. Rock Mech. Geotech. Eng. 2010, 2, 338-349.

17. Zhao, X.G.; Cai, M. Influence of plastic shear strain and confinement-dependent rock dilation on rock failure and displacement near an excavation boundary. Int. J. Rock Mech. Min. Sci. 2010, 47, 723-738. [CrossRef]

18. Meng, Q.; Chen, Y.; Zhang, M.; Han, L.; Pu, H.; Liu, J. On the Kaiser Effect of Rock under Cyclic Loading and Unloading Conditions: Insights from Acoustic Emission Monitoring. Energies 2019, 12, 3255. [CrossRef]

19. Arzua, J.; Alejano, L.R. Dilation in granite during servo-controlled triaxial strength tests. Int. J. Rock Mech. Min. Sci. 2013, 61, 43-56. [CrossRef]

20. Arzua, J.; Alejano, L.R.; Walton, G. Strength and dilation of jointed granite specimens in servo-controlled triaxial tests. Int. J. Rock Mech. Min. Sci. 2014, 69, 93-104. [CrossRef]

21. Pérez-Rey, I.; Alejano, L.R.; Alonso, E.; Arzúa, J.; Araújo, M. An Assessment of the Post-peak Strain Behavior of Laboratory Intact Rock Specimens Based on Different Dilation Models. Procedia Eng. 2017, 191, 394-401. [CrossRef]

22. Lin, P.; Liu, H.; Zhou, W. Experimental study on failure behaviour of deep tunnels under high in-situ stresses. Tunn. Undergr. Space Technol. 2015, 46, 28-45. [CrossRef]

23. Paterson, M.S.; Olgaard, D.L. Rock deformation tests to large shear strains in torsion. J. Struct. Geol. 2000, 22, 1341-1358. [CrossRef]

24. Yi, K.; Kang, H.; Ju, W.; Liu, Y.; Lu, Z. Synergistic effect of strain softening and dilatancy in deep tunnel analysis. Tunn. Undergr. Space Technol. 2020, 97, 103280. [CrossRef]

25. Wang, F.; Qian, D. Difference solution for a circular tunnel excavated in strain-softening rock mass considering decayed confinement. Tunn. Undergr. Space Technol. 2018, 82, 66-81. [CrossRef]

26. Ghanbarian, B.; Lake, L.W.; Sahimi, M. Insights into rock typing: A Critical Study. SPE J. 2019, 24, $230-242$. [CrossRef]

27. Kang, H.; Yi, B.; Gao, F.; Lu, H. Database and characteristics of underground in-situ stress distribution in Chinese coal mines. J. China Coal Soc. 2019, 44, 23-33.

28. Cai, W.; Dou, L.; Ju, Y.; Cao, W.; Yuan, S.; Si, G. A plastic strain-based damage model for heterogeneous coal using cohesion and dilation angle. Int. J. Rock Mech. Min. Sci. 2018, 110, 151-160. [CrossRef]

29. Zou, J.-F.; He, Z. Numerical approach for strain-softening rock with axial stress. Proc. Inst. Civ. Eng. Geotec. 2016, 169, 276-290. [CrossRef]

30. Pourhosseini, O.; Shabanimashcool, M. Development of an elasto-plastic constitutive model for intact rocks. Int. J. Rock Mech. Min. Sci. 2014, 66, 1-12. [CrossRef]

31. Vermeer, P.A. Non-Associated Plasticity for Soils, Concrete and Rock. In Physics of Dry Granular Media; Herrmann, H.J., Hovi, J.P., Luding, S., Eds.; Springer: Dordrecht, The Netherlands, 1998; pp. 163-196.

32. Itasca Inc. FLAC3D: Fast Lagrangian Analysis of Continua in 3 Dimension. Version 5.01; Itasca Inc.: Minneapolis, MN, USA, 2012.

33. Walton, G.; Diederichs, M.S.; Alejano, L.R.; Arzúa, J. Verification of a laboratory-based dilation model for in situ conditions using continuum models. J. Rock Mech. Geotech. Eng. 2014, 6, 522-534. [CrossRef]

34. Kang, H.; Fan, M.; Gao, F.; Zhang, H. Deformation and support of rock roadway at depth more than 1000 meters. Chin. J. Rock Mech. Eng. 2015, 34, 2227-2241.

35. Lu, Y.; Cheng, Y.; Ge, Z.; Cheng, L.; Zuo, S.; Zhong, J. Determination of Fracture Initiation Locations during Cross-Measure Drilling for Hydraulic Fracturing of Coal Seams. Energies 2016, 9, 358. [CrossRef]

(C) 2020 by the authors. Licensee MDPI, Basel, Switzerland. This article is an open access article distributed under the terms and conditions of the Creative Commons Attribution (CC BY) license (http://creativecommons.org/licenses/by/4.0/). 